\title{
Erratum to: Variants of the adiponectin gene and type 2 diabetes in a Polish population
}

\author{
Magdalena Szopa • Malgorzata Malczewska-Malec • \\ Beata Kiec-Wilk • Jan Skupien • Pawel Wolkow • \\ Maciej T. Malecki • Jacek Sieradzki
}

Published online: 29 October 2009

(C) Springer-Verlag 2009

\section{Erratum to: Acta Diabetol}

DOI 10.1007/s00592-008-0091-2

The name of the third author, Beata Kiec-Wilk, was rendered incorrectly in the original publication.

The online version of the original article can be found under doi:10.1007/s00592-008-0091-2.

M. Szopa · J. Skupien · M. T. Malecki $(\bowtie) \cdot$ J. Sieradzki

Department of Metabolic Diseases, Medical College,

Jagiellonian University, 15 Kopernika Street,

31-501 Kraków, Poland

e-mail: malecki_malecki@yahoo.com;

mmalecki@cm-uj.krakow.pl

M. Szopa $\cdot$ M. Malczewska-Malec $\cdot$ B. Kiec-Wilk

Department of Clinical Biochemistry, Medical College,

Jagiellonian University, Kraków, Poland

P. Wolkow

Department of Pharmacology, Medical College,

Jagiellonian University, Kraków, Poland 